\title{
Reconstituindo as teias da relação entreo universal e o singular
}

Silvia Helena Andrade de Brito*

"Agora a nossa realidade se desmorona.

Despencam-se deuses, valores, paredes...

Estamos entre ruínas.

A nós, poetas destes tempos, cabe falar dos morcegos

que voam dentro dessas ruínas.

Dos restos humanos fazendo discursos sozinhos nas ruas. A nós cabe falar do lixo sobrado e dos rios podres que correm por dentro de nós e das casas."

Manoel de Barros

e ao poeta destes tempos cabe alertar sobre a fragmentação da sociedade e, sobretudo, sobre a fragmentação que atinge nossa visão sobre a mesma - tarefa cumprida com maestria pelo cantador do Pantanal, Manoel de Barros -, a perspectiva do pesquisador é procurar compreendê-la. Em outras palavras, como mesmo aponta Gilberto Luiz Alves na obra Mato Grosso do Sul: o universal e o singular, a importância do conhecimento está exatamente em captar a condição humana que nos aproxima, em sua relação com os singulares nos quais esta humanidade vem se expressando, em diferentes espaços e momentos da história.

Esta é a proposta central desta obra: discutir o movimento histórico de como se constituem, em permanente relação, o universal de nossos tempos, a

\footnotetext{
* Departamento de Ciências Humanas e Sociais. CCHS/UFMS. shbrito@terra.com.br
} 
sociedade capitalista, e suas diferentes expressões singulares, marcadas pelas particularidades próprias ao desenrolar da constituição histórica do capital em diferentes paisagens sociais. Ao adentrar tal caminho, contudo, o autor acaba por confrontar-nos com discussões centrais na historiografia atual, de interesse não só àqueles que se dedicam à temática educacional e regional, nas quais Alves tem concentrado seus trabalhos de pesquisa ${ }^{1}$.

Mais que isso, o autor nos brinda com uma reflexão acerca do próprio significado epistemológico e da importância heurística destas duas categorias, universal e singular, dentro do campo teórico marxista. Com isso, apresenta uma discussão profícua para que sejam discutidos os particularismos que ainda hoje se apresentam no campo teórico das Ciências Humanas, ainda mais quando as manifestações de um regionalismo estreito têm impregnado diferentes análises, sob o invólucro da defesa do direito à diferença.

Neste sentido, Alves rejeita qualquer análise que desconsidere o singular e sua importância enquanto espaço de manifestação das leis gerais que operam na sociedade capitalista. Já que o universal, nunca é demais lembrar, encontra aí seu espaço de materialização histórico-social; mas também alerta para o perigo de autonomizar-se o movimento do particular, tornando-o auto-explicativo, perdendo a perspectiva de que seu móvel encontra-se no próprio movimento do todo, encontra-se na sociedade capitalista do qual é parte constituinte. Como forma específica de realização do universal, portanto, os distintos singulares presentes na realidade social estão a ela subordinados, e somente nesta relação dialética serão encontradas as chaves para seu entendimento.

Tais reflexões tornam-se ainda mais interessantes quando ao exercício teórico somam-se os resultados das pesquisas de campo realizadas pelo autor, momento em que expõe seu enfrentamento com os problemas concretos trazidos pela necessidade, imperiosamente colocada ao teórico marxista, de considerar

${ }^{1}$ Eis, a título de exemplo, algumas das obras do autor nestes campos temáticos: ALVES, Gilberto Luiz. Educação e história em Mato Grosso: 1719-1864. 2.ed. rev. Campo Grande: UFMS, 1996.; Id. Mato Grosso e a história: 1870-1929 (Ensaio sobre a transição do domínio econômico da casa comercial à hegemonia do capital financeiro). Boletim Paulista de Geografia, São Paulo, v. 2, n. 61, p. 5-81, 1984; Id. O pensamento burguês no Seminário de Olinda: 1800-1836. 2. ed. rev. Campo Grande: UFMS; Campinas: Autores Associados, 2001.; Id. A produção da escola pública contemporânea. Campinas: Autores Associados, 2001. 
adequadamente a relação universal/singular. Necessidade esta, diga-se de passagem, que vai além do campo meramente explicativo, mas que tem raízes na própria práxis do profissional engajado nos embates sociais de seu tempo.

Como resultado deste confronto, vemo-nos frente a quatro trabalhos, escritos em distintos momentos da vida acadêmica do autor, mas alinhavados teoricamente, como declara este último, pela proposta metodológica de destacar como o marxismo se posiciona frente à relação entre o universal e o singular, objeto de suas reflexões no primeiro texto desta coletânea (Universal e singular: em discussão a abordagem científica do regional). Para a apresentação de suas conclusões, nada melhor do que evidenciar a própria trama de que resulta o processo de formação e consolidação da sociedade capitalista, materializada nas expressões singulares que conformaram esta mesma sociedade no Novo Mundo. Estas últimas são trazidas à cena histórica, por um lado, fazendo menção àquilo que universaliza a ação humana nesta parte do globo, ou seja, as manifestações do capital enquanto elemento inerente e essencial no processo societário em curso; por outro, este capital, na sua dinâmica concreta, encontrou sua materialidade nas formas distintas por meio das quais expressou-se nesta parte do mundo, manifestas na atividade jesuítica, nas diferentes formas de colonização das Américas, na maneira como se deu a utilização da força de trabalho índia, negra ou imigrante, ou mais modernamente, como se expressou no continente a doutrina de segurança nacional.

$\mathrm{O}$ autor destaca, contudo, a necessidade de que sejam desveladas, neste esforço teórico-metodológico, as representações ideológicas que reforçam o estranhamento entre os povos americanos, na medida em que desviam a atenção do pesquisador da relação dialética necessária entre o singular e o universal. $\mathrm{Na}$ verdade, os regionalismos, os nacionalismos, em seus diferentes matizes, levam ao esquecimento da necessidade de se enfatizar a subordinação dos distintos singulares ao movimento universal da sociedade capitalista, uma vez que estes singulares são formas de realização desta mesma sociedade. Na práxis política, destaca ainda, isso significa a construção das bases para uma ação política significativa para o conjunto da humanidade, isto é, capaz de colaborar para o projeto emancipatório do homem hodierno.

O segundo texto (Nacional e regional na historiografia educacional brasileira: uma análise sob a ótica dos estados mato-grossenses) promove

Albuquerque: revista de História, Campo Grande, MS, v. 1, n. 1, p. 229-235, jan./jun. 2009231 
um balanço da historiografia educacional produzida no e sobre os estados de Mato Grosso e Mato Grosso do Sul, entre os anos 70 e 90. O critério a partir do qual esta parcela da historiografia regional será analisada está centrado na relação universal/singular, desta feita discutida a partir de algumas das expressões desta singularidade, a questão regional e a questão educacional.

Com base nestas premissas é discutida a historiografia sobre esta região do país, tanto aquela que teve a educação como objeto como aquela que, embora não centrada nos fenômenos educativos, é essencial para que se compreenda a constituição do processo capitalista nesta parte do Brasil. Revelam-se assim, no exercício cotidiano da pesquisa em História da Educação, os liames que permitem reconstituir os processos educativos em curso naquela determinada região do país, em determinado momento de sua história, a partir da reconstituição das relações que os processos em foco guardam com a totalidade da sociedade capitalista.

Para esta exposição, são retomadas as obras da historiografia educacional diletante, marcadas essencialmente pelo registro e reconstituição factual da história. Entre estes trabalhos que antecederam a produção acadêmica destaca-se a obra de Melo e Silva, único intelectual a lançar-se à análise do momento histórico que era foco de suas preocupações - a década de 40 do século XX, em especial na fronteira sul do então estado de Mato Grosso, obra que ainda permanece como um desafio para a historiografia regional, dada esta sua especificidade.

O surgimento da produção acadêmica a partir dos anos 70 , fortalecida na década seguinte pelo aparecimento dos primeiros cursos de pós-graduação naqueles estados, dá ensejo não só ao maior conhecimento e problematização da questão educativa regional, como à sua incorporação no debate nacional. A formação de coletivos de pesquisa, o levantamento de fontes para a pesquisa, a organização de arquivos, centros de documentação, entre outras iniciativas, fortaleceu a discussão sobre os entraves representados pelo regionalismo, e a necessidade do fortalecimento da discussão acerca da relação universal/singular, no entendimento das formas assumidas pelo processo educativo nos dois estados.

Além disso, mais recentemente, como o demonstra este próprio texto, escrito por ocasião do I Congresso Nacional de História da Educação, realizado sob os auspícios da Sociedade Brasileira de História da Educação (SBHE), as reflexões sobre a historiografia educacional mato-grossense e sul-mato-grossense, na 
medida em que desvele as singularidades assumidas pelo processo educativo nestas regiões do Brasil, pode contribuir para iluminar a produção historiográfica sobre o tema em todo o país, em dois sentidos. Primeiro, ao levantar hipóteses de trabalho sobre como fenômenos produzidos nacionalmente, fruto do processo de expansão capitalista, singularizam-se nestes estados, e de como estas singularidades podem ou não tornarem-se expressões presentes em outras regiões do Brasil. Segundo, colaborando para que certas idéias que se tornaram comuns na historiografia educacional brasileira sejam confrontadas com sua materialidade, $\mathrm{o}$ que pode favorecer a crítica científica de certos equívocos que vem se perpetuando entre os estudiosos da área.

O terceiro texto retoma a mesma discussão sobre o singular e o universal, desta feita ao tratar sobre A trajetória histórica do grande comerciante dos portos em Corumbá: 1857-1929.

Tendo como preocupação central analisar o surgimento da casa comercial em Corumbá, na segunda metade do século XIX, o autor demonstra, em um texto de rara inspiração, os liames que fazem desta uma expressão, no distante Mato Grosso, do período de transição da fase manufatureira para aquela centrada na Revolução Industrial, ou seja, na produção de bens industrializados, no interior da etapa concorrencial do capitalismo.

Alves demonstra, recorrendo a exemplos relativos ao mesmo fenômeno em outras partes do continente sul-americano, como se deu a formação, o desenvolvimento e, posteriormente, o ocaso desta atividade comercial que marcou tão intensamente a vida daquela região de Mato $\mathrm{Grosso}^{2}$. O autor destaca ainda como essas marcas provocaram a cosmopolitização da vida em Corumbá, dando ensejo a manifestações culturais e sociais até hoje presentes naquele município fronteiriço, como é o caso do conjunto arquitetônico denominado Casario do Porto. No momento em que se discutem propostas de revitalização destas e de outras edificações em Corumbá, nada mais importante do que se ter sob os olhos este passado, base para as reflexões presentes sobre o seu uso continuado e, acima de tudo, centrado nos interesses de construção de uma sociedade cidadã.

\footnotetext{
${ }^{2}$ Trata-se aqui do estado de Mato Grosso antes do processo de divisão, ocorrida em 1979, que deu origem a duas unidades federativas: Mato Grosso e Mato Grosso do Sul.
} 
No quarto e último texto o autor volta suas preocupações aos primórdios da atividade que, em momento histórico posterior ao comércio, virá a ser determinante na região pantaneira. Estamos falando da pecuária na segunda metade do século XIX, e sobre um de seus principais mentores no Pantanal neste período, temas do trabalho José de Barros: a formação de um pioneiro.

Sobre os destaques deste texto, é interessante assinalar, primeiramente, a utilização sistemática da obra de cronistas e viajantes para descrever aspectos da região neste momento histórico, destacando a forma como se davam as relações humanas nesta etapa da sociedade capitalista no Pantanal. Em outras palavras, como se singularizou, na região da Nhecolândia, uma determinada forma de expressão, particular a este espaço e momento histórico, da sociedade capitalista.

Num segundo momento, Alves demonstra ainda como os limites materiais impostos a esses homens neste processo de formação e consolidação das fazendas de gado levaram-nos a determinadas soluções no processo de recolonização da região. Neste sentido, por exemplo, embora valorizasse o ensino formal, - traço este que parece ter destacado a sua família frente a outros pioneiros -, José de Barros teve que abandonar a escola regular, após ter aprendido os seus fundamentos (ler, escrever e realizar as quatro operações aritméticas), dados os precários recursos materiais de sua família.

As necessidades impostas pelas dificuldades inerentes ao trabalho com a família lhe impuseram continuar sua formação na "escola do trabalho", aquela que lhe permitiria, junto aos conhecimentos e hábitos adquiridos graças à escola regular, alguns anos depois, criar as condições concretas para o sustento e a formação de uma vasta prole, criada e ambientada na região pantaneira.

À guisa de conclusão, consideramos aqui as palavras iniciais do autor quando, na página de abertura da obra Mato Grosso do Sul: o universal e o singular, dedica seu trabalho ao poeta Manoel de Barros, "poeta que se universalizou ao cantar o Pantanal." Da mesma forma, cremos que Alves, partindo de uma discussão centrada na temática regional, - intenção claramente exposta desde o início no próprio título dado a este trabalho, - tenha alcançado seu intento de demonstrar e discutir questões que são de interesse para pesquisadores de todas as áreas do conhecimento. Em outras palavras, o autor também se universaliza, 
trazendo a baila um trabalho que, pelo rigor com que discute uma questão central no universo metodológico marxista, contribui para o debate teórico enfrentado pelos estudiosos de hoje, sejam quais forem seus recortes temáticos específicos. Neste sentido, torna-se uma obra importante para quantos tenham interesse de trabalhar, teórica e ou praticamente, a relação entre o singular e o universal na pesquisa científica. 